\title{
Risk factors for postoperative sepsis-induced cardiomyopathy in patients undergoing general thoracic surgery: a single center experience
}

\author{
Yinghua Wang ${ }^{1,2} \wedge$, Xinming Zhai ${ }^{2}$, Minfang $Z^{2}{ }^{2}$, Yan Pan $^{3}$, Min Yang ${ }^{2}$, Kaiyan Yu ${ }^{2}$, Ben $\mathrm{He}^{1}$ \\ ${ }^{1}$ Department of Cardiology, Shanghai Chest Hospital, Shanghai Jiao Tong University, Shanghai, China; ${ }^{2}$ Department of Intensive Care Medicine, \\ Shanghai Chest Hospital, Shanghai Jiao Tong University, Shanghai, China; ${ }^{3}$ Department of Pharmacy, Shanghai Chest Hospital, Shanghai Jiao Tong \\ University, Shanghai, China \\ Contributions: (I) Conception and design: Y Wang, B He, K Yu; (II) Administrative support: None; (III) Provision of study materials or patients: \\ None; (IV) Collection and assembly of data: Z Min, M Zhu; (V) Data analysis and interpretation: Y Pan, Y Wang; (VI) Manuscript writing: All \\ authors; (VII) Final approval of manuscript: All authors. \\ Correspondence to: Ben He. Department of Cardiology, Shanghai Chest Hospital, Shanghai Jiao Tong University, 10th Floor, No. 5 Building, \\ No. 241, West Huai Hai Rd, Xuhui District, Shanghai, China. Email: heben241@126.com; Kaiyan Yu. Department of Intensive Care Medicine, \\ Shanghai Chest Hospital, Shanghai Jiao Tong University, 2rd Floor, No. 2 Building, No. 241, West Huai Hai Rd, Xuhui District, Shanghai, China. \\ Email: kyy20@163.com.
}

Background: The current study aimed to investigate the incidence of sepsis-induced cardiomyopathy (SICM) in patients who received general thoracic surgery, along with the risk factors and management strategies for this complication.

Methods: The clinical records of 163 patients with postoperative sepsis were retrospectively reviewed. After propensity score matching, 144 patients were divided into 2 groups by stroke volume: the SICM group $(\mathrm{n}=72)$ and the non-SICM group $(\mathrm{n}=72)$.

Results: The overall incidence of postoperative SICM was 53.99\%. Multiple logistic regression analysis showed that stroke volume and C-reactive protein were independent predictors of mortality in patients with postoperative sepsis. Statistical analysis by $t$-test and $\chi^{2}$ test indicated that mortality $(\mathrm{P}=0.000)$, B-type natriuretic peptide $(\mathrm{P}=0.001)$, left ventricular ejection fraction $(\mathrm{P}=0.000)$, the mitral peak velocity of early filling/early diastolic mitral annular velocity (E/e') $(\mathrm{P}=0.049)$, C-reactive protein $(\mathrm{P}=0.016)$, procalcitonin $(\mathrm{P}=0.013)$, serum creatinine $(\mathrm{P}=0.016)$, platelets $(\mathrm{P}=0.028)$, and lactic acid $(\mathrm{P}=0.002)$ were significantly associated with the occurrence of postoperative SICM. Among these parameters, B-type natriuretic peptide was identified as the best biomarker for predicting SICM by receiver operating characteristic (ROC) curve analysis.

Conclusions: It is vital to improve the diagnosis and standard management of SICM. A combined strategy comprising early detection of suspected infection, adequate use of antibiotics, close monitoring, effective drainage, and supportive care may improve the outcomes of patients with postoperative SICM.

Keywords: Risk factor; sepsis-induced cardiomyopathy (SICM); general thoracic surgery

Submitted Mar 01, 2021. Accepted for publication Apr 21, 2021.

doi: $10.21037 /$ jtd-21-492

View this article at: http://dx.doi.org/10.21037/jtd-21-492

\footnotetext{
$\wedge$ ORCID: 0000-0003-1923-1477.
} 


\section{Introduction}

Sepsis has a massive impact on human lives worldwide and results in millions of deaths each year. The definition and diagnosis of sepsis have evolved through 3 historic stages. In Sepsis 1.0, the initial definition, sepsis was viewed as resulting from systemic inflammatory response syndrome to infection. In 2001, the $2^{\text {nd }}$ consensus was formalized, expanding the diagnostic criteria. It was not until 2014, when the $3^{\text {rd }}$ definition was published, that sepsis was recognized as life-threatening organ dysfunction caused by a dysregulated host response to infection. Sepsis 3.0, which was released in 2016, established sepsis as a syndrome shaped by host factors and pathogenic infection which leads to organ dysfunction, and also updated our knowledge of septic shock $(1,2)$.

Sepsis-induced cardiomyopathy (SICM), or sepsisinduced myocardial dysfunction, was first recognized in 1984. Multiple mechanisms have been proposed in SICM, such as systemic inflammation, oxidative stress and mitochondria dysfunction. However, it still lacks definitive diagnostic criteria. Consequently, SICM is often underdiagnosed or missed during regular clinical work, and it is believed to result in high mortality (3). Most experts agree that characteristics of SICM include acute and reversible cardiac dysfunction within 7 to 10 days after sepsis, with left ventricular dilation, global dysfunction, or reduced contractility. Patients with SICM rely on catecholamines and have diminished responses to fluid resuscitation (4). In this single-center study, we retrospectively analyzed data of patients who had developed postoperative SICM after undergoing general thoracic surgical procedures (in the lung, esophagus, trachea, and mediastinum) between 2018 and 2019. We present the following article in accordance with the STROBE reporting checklist (available at http://dx.doi.org/10.21037/jtd-21-492).

\section{Methods}

From October 2018 to October 2019, 15,484 consecutive patients received general thoracic surgery in Shanghai Chest Hospital, Shanghai Jiao Tong University. Among them, 163 patients with sepsis were enrolled into the present study. This study was approved by Shanghai Chest Hospital Clinical Research Ethics Committee (No. IS2115) and was conducted in accordance with the provisions of the Declaration of Helsinki (as revised in 2013). Individual consent for this retrospective analysis was waived.

Sepsis was defined according to Sepsis 3.0, i.e., a change in sepsis-related organ failure assessment (SOFA) score $\geq 2$ points as a consequence of infection. Patients who were previously diagnosed with structural heart disease, coronary artery disease, or preoperative cardiac dysfunction were excluded.

\section{Acquisition of clinical data}

Sepsis severity was determined according to the SOFA score (Table 1). During sepsis, troponin I (TnI) and B-type natriuretic peptide (BNP) were measured, and echocardiography was performed. SICM was confirmed by echocardiography. Echocardiographic measurements were performed using a GE ultrasound system (Vivid 9, GE, Norway). Stroke volume (SV), left ventricular ejection fraction (LVEF), and the mitral peak velocity of early filling/early diastolic mitral annular velocity (E/e') (e' was obtained by Tissue Doppler imaging) were calculated from the apical 4-chamber view using Simpson's method. Since LVEF is often "better" than preoperative LVEF in patients with sepsis, we chose SV for grouping. Taking $60-80 \mathrm{~mL}$ as the normal SV and SV $<60 \mathrm{~mL}$ as SICM, after propensity score matching, we divided the patients into 2 groups: the SICM group ( $\mathrm{SV}<60 \mathrm{~mL}$ ) and the non-SICM group (SV $\geq 60 \mathrm{~mL}$ ). Twenty-one perioperative characteristics were compared between the 2 groups.

\section{Statistical analysis}

All statistical analyses were performed with SPSS 25.0 (IBM, USA) for Windows. Quantitative variables were described as means and standard deviations. The test of homogeneity variance was used to determine the distribution of quantitative data. When variables had a normal distribution, the independent-samples $t$-test was used to compare the quantitative sizes of 2 independent samples. The dependence of qualitative variables was assessed using the chi-square $\left(\chi^{2}\right)$ criterion. Multivariate stepwise forward logistic regression analysis was adopted for the identification of independent risk factors for perioperative survival in our center. To reduce the influence of confounding factors, propensity score matching was carried out (Tables 2,3). Receiver operating characteristic (ROC) curves were drawn to assess the sensitivity and specificity of predictors of SICM.

\section{Results}

Between October 2018 and October 2019, 163 consecutive 
Table 1 Sepsis-related organ failure assessment (SOFA) score

\begin{tabular}{|c|c|c|c|c|c|}
\hline System & \multicolumn{5}{|c|}{ Score } \\
\hline $\begin{array}{l}\text { Respiration } \mathrm{PaO}_{2} / \mathrm{FiO}_{2} \\
(\mathrm{mmHg})\end{array}$ & $\geq 400$ & $<400$ & $<300$ & $<200$ with respiratory support & $<100$ with respiratory support \\
\hline $\begin{array}{l}\text { Coagulation platelets } \\
\left(10^{9} / \mathrm{L}\right)\end{array}$ & $\geq 150$ & $<150$ & $<100$ & $<50$ & $<20$ \\
\hline Cardiovascular & $\begin{array}{c}\text { MAP } \\
\geq 70 \mathrm{mmHg}\end{array}$ & $\begin{array}{c}\text { MAP } \\
<70 \mathrm{mmHg}\end{array}$ & $\begin{array}{l}\text { Dopamine or } \\
\text { dobutamine } \\
<5 \mu \mathrm{g} / \mathrm{kg} / \mathrm{min}\end{array}$ & $\begin{array}{l}\text { Dopamine } 5.1-15 \mu \mathrm{g} / \mathrm{kg} / \mathrm{min} \text { or } \\
\text { epinephrine } \leq 0.1 \mu \mathrm{g} / \mathrm{kg} / \mathrm{min} \text { or } \\
\text { norepinephrine } \leq 0.1 \mu \mathrm{g} / \mathrm{kg} / \mathrm{min}\end{array}$ & $\begin{array}{l}\text { Dopamine }>15 \mu \mathrm{g} / \mathrm{kg} / \mathrm{min} \text { or } \\
\text { epinephrine }>0.1 \mu \mathrm{g} / \mathrm{kg} / \mathrm{min} \text { or } \\
\text { norepinephrine }>0.1 \mu \mathrm{g} / \mathrm{kg} / \mathrm{min}\end{array}$ \\
\hline $\begin{array}{l}\text { CNS (Glasgow coma } \\
\text { scale score) }\end{array}$ & 15 & $13-14$ & $10-12$ & $6-9$ & $<6$ \\
\hline Urine output (mL/d) & & & & $<500$ & $<200$ \\
\hline
\end{tabular}

$\mathrm{PaO}_{2}$, partial pressure of oxygen; $\mathrm{FiO}_{2}$, fraction of inspired oxygen; MAP, mean arterial pressure; CNS, central nervous system.

Table 2 Propensity score matching of patients with postoperative sepsis (case-control matching statistics)

\begin{tabular}{lc}
\hline Match type & Count \\
\hline Exact matches & 10 \\
Fuzzy matches & 62 \\
Unmatched, including missing keys & 3 \\
Unmatched with valid keys & 3 \\
Sampling & Without replacement \\
Log file & None \\
Maximized matching performance & Yes \\
\hline
\end{tabular}

patients who developed sepsis after undergoing general thoracic surgical procedures, including lung, esophageal, tracheal and mediastinal operations, in Shanghai Chest Hospital were included in our study. The patients ranged in age from 22 to 87 years old, with a mean age of $64.32 \pm 9.93$ years old. Males accounted for $84.7 \%$ of enrollees.

For the patients in the study, the mean SOFA score was $5.94 \pm 1.85$. The overall in-hospital mortality rate was $32.5 \%$. The incidence of postoperative SICM was $53.99 \%$. Perioperative characteristics of the patients are shown in Table 4. Multivariate logistic regression analysis revealed SV and C-reactive protein (CRP) to be independent predictors of mortality in patients with postoperative sepsis (Table 5).
To determine the risk factors associated with postoperative SICM, after propensity score matching, 144 patients were divided into 2 groups by SV: the SICM group $(\mathrm{n}=72)$ and the non-SICM group $(\mathrm{n}=72)$. Univariate analysis revealed significant differences between the 2 groups with respect to the following clinical variables: mortality $(\mathrm{P}=0.000), \mathrm{BNP}(\mathrm{P}=0.001)$, LVEF $(\mathrm{P}=0.000), \mathrm{E} / \mathrm{e}$ ' ratio $(\mathrm{P}=0.049)$, CRP $(\mathrm{P}=0.016)$, procalcitonin (PCT) $(\mathrm{P}=0.013)$, serum creatinine $(\mathrm{P}=0.016)$, platelets $(\mathrm{P}=0.028)$, and lactic acid ( $\mathrm{Lac})(\mathrm{P}=0.002)$ (Table 6). Among the variables examined in the ROC curve analysis, BNP had the highest area under the ROC curve (AUC) value (AUC: 0.707, 95\% CI: 0.581-0.834) (Figure 1), suggesting that it might be the best biomarker for SICM.

\section{Discussion}

SICM is defined as reversible myocardial systolic and diastolic dysfunction caused by sepsis. Previous studies have shown that approximately $50 \%$ of patients with sepsis exhibit signs of myocardial dysfunction, such as poor systolic or diastolic function, ventricular dilation, and a poor response to resuscitation with fluids and catecholamines $(5,6)$. However, in the absence of definitive diagnostic criteria, SICM is often underdiagnosed or missed during regular clinical work. Few studies have reviewed the clinical data of SICM after general thoracic surgery. Therefore, our study set out to determine the incidence of SICM among 
Table 3 Propensity score matching of patients with postoperative sepsis (case-control match tolerances)

\begin{tabular}{lccc}
\hline Match variables & Value & Fuzzy match tries & Incremental rejection percentage \\
\hline Exact (all variables) & 0 & 438.000 & 97.717 \\
PS & 0.020 & 428.000 & 85.514 \\
\hline
\end{tabular}

Tries is the number of match comparisons before drawing. Rejection percentage is the match rejection rate. Rejections are attributed to the first variable in the BY list that causes rejection.

Table 4 Perioperative characteristics of patients with postoperative sepsis

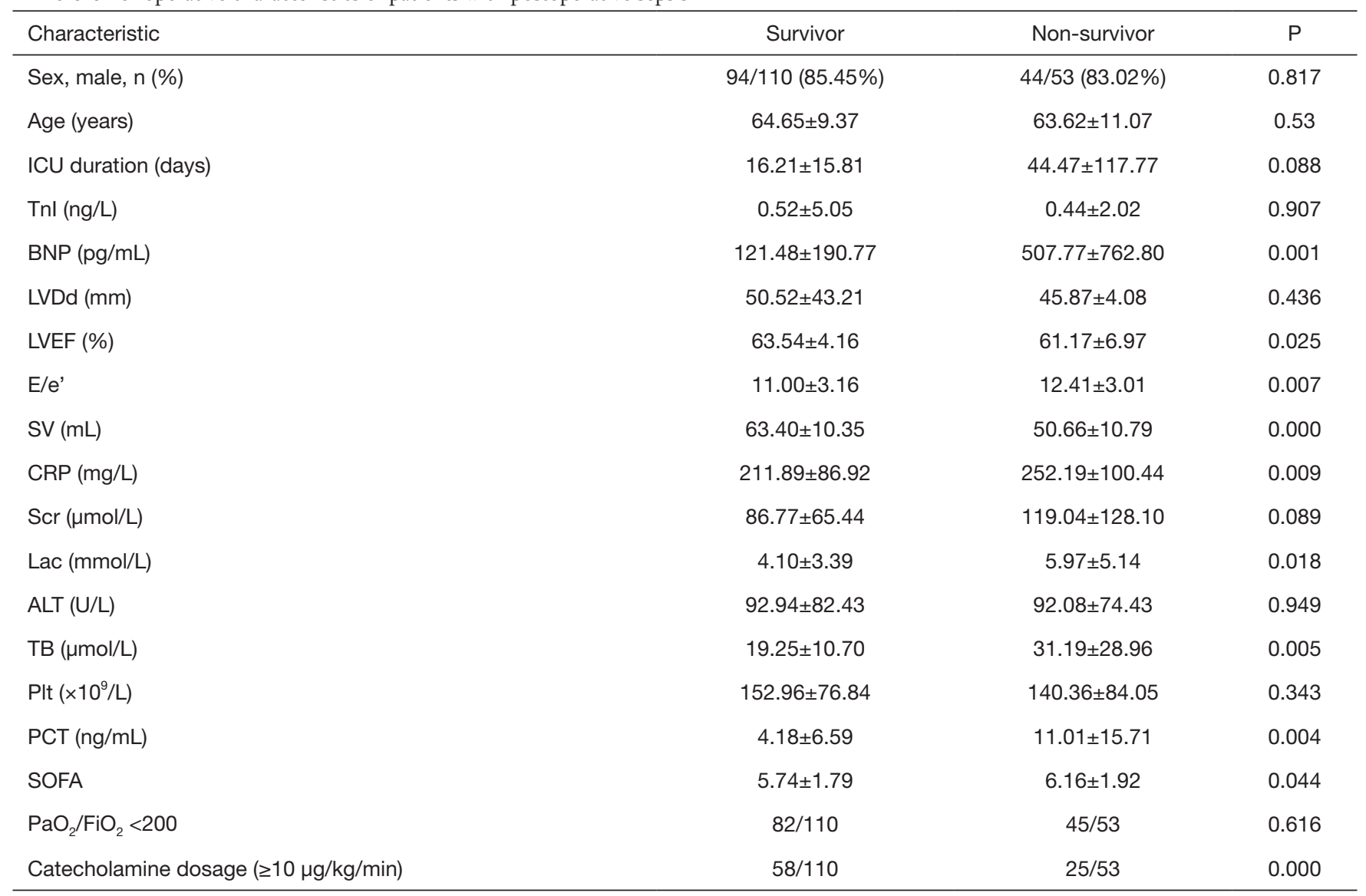

SV, stroke volume; ICU, intensive care unit; Tnl, troponin; BNP, B-type natriuretic peptide; LVDd, left ventricular diastolic diameter; LVEF, left ventricular ejection fraction; E/e', the mitral peak velocity of early filling/early diastolic mitral annular velocity; CRP, C-reactive protein; Scr, serum creatinine; Lac, lactic acid; ALT, alanine aminotransferase; TB, total bilirubin; PIt, platelet; PCT, procalcitonin; SOFA, sepsisrelated organ failure assessment (SOFA) score; $\mathrm{PaO}_{2}$, partial pressure of oxygen; $\mathrm{FiO}_{2}$, fraction of inspired oxygen.

patients with sepsis following thoracic surgery, and to identify the risk factors and potential management strategies for SICM.

Sepsis is a hyperdynamic process characterized by an increase in cardiac output and low systemic vascular resistance (7-9). Septic shock is a type of sepsis that manifests with unstable hemodynamics and abnormal metabolism $(10,11)$, for which the mortality rate exceeds $40 \%$. Sepsis 3.0 updated our knowledge of sepsis and septic shock. The most popular scoring systems for assessing critically ill patients are APACHE II (Acute Physiology and Chronic Evaluation Scoring System II) and the SOFA score. The SOFA score has been proposed as a rapid clinical scoring system for the prognostic stratification of patients 
Table 5 Multivariate logistic regression analysis of mortality risk factors in postoperative sepsis

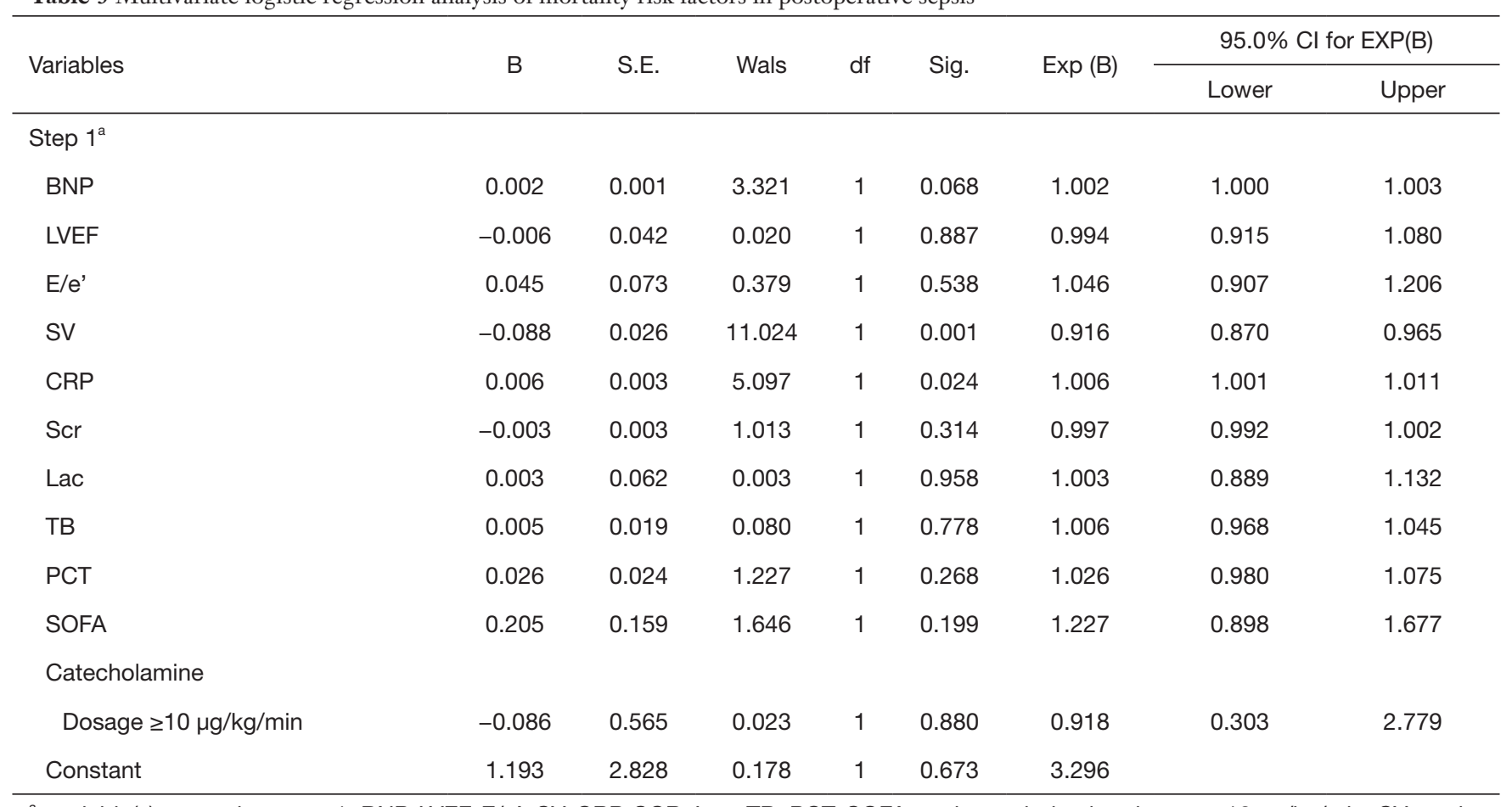

a, variable(s) entered on step 1: BNP, LVEF, E/e', SV, CRP, SCR, Lac, TB, PCT, SOFA, and catecholamine dosage $\geq 10 \mu \mathrm{gg} / \mathrm{kg} / \mathrm{min}$. SV, stroke volume; BNP, B-type natriuretic peptide; LVEF, left ventricular ejection fraction; E/e', the mitral peak velocity of early filling/early diastolic mitral annular velocity; CRP, C-reactive protein; Scr, serum creatinine; Lac, lactic acid; TB, total bilirubin; PCT, procalcitonin; SOFA, sepsisrelated organ failure assessment (SOFA) score.

with sepsis (12). Organ dysfunction can be identified by an acute change consequent to infection. A SOFA score $\geq 2$ reflects an overall mortality risk of approximately $10 \%$ in patients with infection (12). A high SOFA score is often associated with mortality. Therefore, our study enrolled patients with postoperative sepsis who had a SOFA score $\geq 2$. Previous reports have shown that cardiac TnI is correlated with a high degree of left ventricle dysfunction, severity, and mortality in patients with sepsis (13). BNP also has prognostic value in sepsis $(14,15)$. Some studies have already assessed diastolic function in SICM $(4,16,17)$. A reduced e wave $\left(\mathrm{e}^{\prime}<8 \mathrm{~cm} / \mathrm{s}\right)$ and an increased $\mathrm{E} / \mathrm{e}^{\prime}$ ratio are common findings in patients with sepsis and are strong predictors of diastolic cardiac dysfunction in septic shock (18). Recently, an increasing number of studies have focused on right ventricular dysfunction in patients with sepsis $(19,20)$. In the current study, the overall mortality rate among the 163 patients enrolled was $32.5 \%$. SV and CRP were identified as independent predictors of postoperative sepsis outcome. Further, E/e', BNP, LVEF, SOFA, Lac, PCT, and TB were also found to be associated with mortality. Among these mortality-associated variables, LVEF, SV, E/e', and BNP were uncovered as risk factors for SICM. The E/e' ratio was used as an index of $\mathrm{LV}$ filling pressure and a measure of diastolic dysfunction. E/e' $>8$ means impaired diastolic reserve with the inability to increase $\mathrm{SV}$ after a fluid bolus.

In sepsis, relative hypovolemia and a reduction in vascular tone may result in preserved ejection fraction, temporarily masking cardiac dysfunction. SV and its surrogates are known to perform well as predictors of cardiac function, preload, and fluid responsiveness $(17,21)$. Thus, SV acquired by echocardiography was chosen to group the patients. In this study, $\mathrm{SV}<60 \mathrm{~mL}$ identified patients as SICM. The survival rate, BNP, LVEF, E/e', Scr, Lac, Plt, PCT, and CRP differed significantly between the 2 groups, suggesting that multiple organ dysfunction, metabolic disorders, and infection were more severe in the SICM group. Moreover, BNP appeared to be the best biomarker for predicting the occurrence of SICM.

The Surviving Sepsis Campaign guidelines recommend 3 - or 6-hour bundle therapy with Dr. River's early goal-directed therapy (22-25). Standard early goal- 
Table 6 Perioperative characteristics of the patients with sepsis and univariate analysis of risk factors for postoperative sepsis-induced cardiac dysfunction

\begin{tabular}{|c|c|c|c|}
\hline Characteristic & SV $\geq 60 \mathrm{~mL}(\mathrm{n}=72)$ & $\mathrm{SV}<60 \mathrm{~mL}(\mathrm{n}=72)$ & $P$ \\
\hline Age (years) & $64.42 \pm 9.32$ & $63.92 \pm 9.78$ & 0.754 \\
\hline ICU duration (days) & $17.36 \pm 17.83$ & $35.89 \pm 101.97$ & 0.133 \\
\hline Tnl (ng/L) & $0.76 \pm 6.24$ & $0.13 \pm 0.48$ & 0.392 \\
\hline LVDd (mm) & $47.43 \pm 2.68$ & $51.82 \pm 53.47$ & 0.488 \\
\hline LVEF (\%) & $64.45 \pm 3.36$ & $61.39 \pm 6.26$ & 0.000 \\
\hline$E / e^{\prime}$ & $10.72 \pm 2.94$ & $11.74 \pm 3.25$ & 0.049 \\
\hline CRP (mg/L) & $208.86 \pm 86.00$ & $245.38 \pm 94.00$ & 0.016 \\
\hline ALT (U/L) & $84.68 \pm 84.32$ & $97.46 \pm 70.43$ & 0.325 \\
\hline TB $(\mu \mathrm{mol} / \mathrm{L})$ & $20.18 \pm 12.30$ & $23.36 \pm 14.89$ & 0.165 \\
\hline Plt $\left(\times 10^{9} / L\right)$ & $165.25 \pm 85.93$ & $136.33 \pm 69.97$ & 0.028 \\
\hline PCT (ng/mL) & $3.81 \pm 2.53$ & $7.94 \pm 13.58$ & 0.013 \\
\hline SOFA & $5.83 \pm 1.73$ & $6.00 \pm 1.89$ & 0.582 \\
\hline $\mathrm{PaO}_{2} / \mathrm{FiO}_{2}<200$ & $54 / 72$ & $57 / 72$ & 0.552 \\
\hline \multicolumn{4}{|l|}{ Catecholamine } \\
\hline Dosage $(\geq 10 \mu \mathrm{g} / \mathrm{kg} / \mathrm{min})$ & $43 / 72$ & $32 / 72$ & 0.067 \\
\hline
\end{tabular}

SV, stroke volume; ICU, intensive care unit; Tnl, troponin; BNP, B-type natriuretic peptide; LVDd, left ventricular diastolic diameter; LVEF, left ventricular ejection fraction; E/e', the mitral peak velocity of early filling/early diastolic mitral annular velocity; CRP, C-reactive protein; Scr, serum creatinine; Lac, lactic acid; ALT, alanine aminotransferase; TB, total bilirubin; PIt, platelet; PCT, procalcitonin; SOFA, sepsisrelated organ failure assessment (SOFA) score; $\mathrm{PaO} 2$, partial pressure of oxygen; FiO2, fraction of inspired oxygen.

directed therapy includes vasopressors, inotropes, and fluid resuscitation $(30 \mathrm{~mL} / \mathrm{kg}$ bolus of crystalloid fluid administration within 3 hours of sepsis presentation to correct hypotension). However, fluid resuscitation and vasopressors may not always be sufficient to reverse cardiac dysfunction in patients with SICM, and unfortunately, excessive volume or afterload by fluid resuscitation may exacerbate mortality in $\operatorname{SICM}(4,26)$.

In our practice, we focus on the clinical manifestations of both infection and organ dysfunction. For patients who remain hypotensive after initial fluid resuscitation, echocardiography and heart-related biomarkers may aid in recognizing cardiac dysfunction and determining the necessity for inotropes to be administrated. Echocardiography is the cornerstone for the diagnosis of SICM. There is a consensus that all patients who are hemodynamically unstable should receive critical care echocardiography. Hence, besides the standard management, it is equally important to improve diagnostic approaches to SICM. Also, effective drainage and supportive care are essential for patients following surgery. Drainage may sometimes be more efficient than broad-spectrum antibiotics. Supportive care, such as invasive positive pressure ventilation and continuous renal replacement therapy, can be prescribed to improve cardiac function and control systemic inflammatory response. Also, extracorporeal membrane oxygenation may be able to provide hemodynamic rescue for patients who are critically ill with $\operatorname{SICM}(4,27)$. 


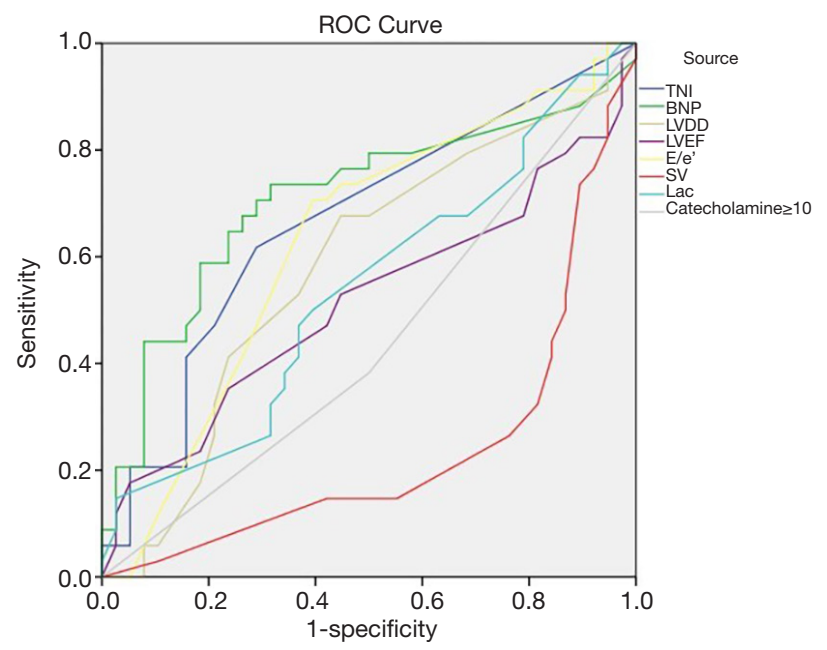

Area under the curve

\begin{tabular}{llllll}
\hline \multirow{2}{*}{ Variable } & AUC & STE $^{\mathrm{a}}$ & Sig. $^{\mathrm{b}}$ & \multicolumn{2}{c}{$95 \% \mathrm{Cl}$} \\
\cline { 5 - 6 } Tnl & & & & Lower $^{\text {Upper }}$ \\
BNP & 0.666 & 0.065 & 0.016 & 0.538 & 0.793 \\
LVDD & 0.707 & 0.064 & 0.003 & 0.581 & 0.834 \\
LVEF & 0.584 & 0.068 & 0.221 & 0.450 & 0.718 \\
E/e' & 0.515 & 0.070 & 0.822 & 0.377 & 0.653 \\
Lac & 0.628 & 0.067 & 0.061 & 0.497 & 0.760 \\
Catecholaminedosage $\geq 10 \mu \mathrm{g} / \mathrm{kg} / \mathrm{min}$ & 0.539 & 0.069 & 0.573 & 0.404 & 0.673 \\
SOFA & 0.441 & 0.068 & 0.391 & 0.308 & 0.575 \\
SV & 0.567 & 0.068 & 0.332 & 0.433 & 0.703 \\
\hline
\end{tabular}

Figure 1 Receiver operating characteristic curves for predictors of sepsis-induced cardiac dysfunction. AUC, area under the receiver operating characteristic curve; STE, standard error ( ${ }^{\mathrm{a}}$, under nonparametric assumption); Sig., significance ( ${ }^{\mathrm{b}}$, null hypothesis, acual area =0.5); SV, stroke volume; TnI, troponin; BNP, B-type natriuretic peptide; LVDd, left ventricular diastolic diameter; LVEF, left ventricular ejection fraction; E/e', the mitral peak velocity of early filling/early diastolic mitral annular velocity; Lac, lactic acid; SOFA, sepsis-related organ failure assessment (SOFA) score.

\section{Conclusions}

In the present study, over $50 \%$ of patients with sepsis exhibited signs of myocardial dysfunction. SV and CRP may be 2 independent predictors of outcomes in postoperative sepsis. $\mathrm{BNP}$ is potentially the best biomarker for predicting the occurrence of SICM. A combined strategy comprising early detection of suspected infection, adequate use of antibiotics, close monitoring, effective drainage, and supportive care may improve the outcomes of patients with postoperative SICM.

\section{Limitations}

This research has several limitations. First, the patient population enrolled for analysis was small, and propensity score matching resulted in slight shrinking of the data. Second, this is a single-center investigation. Third, owing to their critical status, the patients in this study did not undergo full examinations. Finally, as this is a retrospective study, potential bias from misclassification could not be completely excluded. 


\section{Acknowledgments}

We would like to thank all the surgeons in the Department of Thoracic Surgery in Shanghai Chest Hospital, who perform more than 15,000 surgeries every year.

Funding: This work was supported by grants from the National Natural Science Foundation of China (81830010), the Science and Technology Commission of Shanghai Municipality (18411950400), and the Clinical Research Plan of SHDC (16CR1012A).

\section{Footnote}

Reporting Checklist: The authors have completed the STROBE reporting checklist. Available at http://dx.doi. org/10.21037/jtd-21-492

Data Sharing Statement: Available at http://dx.doi. org/10.21037/jtd-21-492

Conflicts of Interest: All authors have completed the ICMJE uniform disclosure form (available at http://dx.doi. org/10.21037/jtd-21-492). The authors have no conflicts of interest to declare.

Ethical Statement: The authors are accountable for all aspects of the work in ensuring that questions related to the accuracy or integrity of any part of the work are appropriately investigated and resolved. The study was conducted in accordance with the Declaration of Helsinki (as revised in 2013). This study was approved by Shanghai Chest Hospital Clinical Research Ethics Committee (No. IS2115). Individual consent for this retrospective analysis was waived.

Open Access Statement: This is an Open Access article distributed in accordance with the Creative Commons Attribution-NonCommercial-NoDerivs 4.0 International License (CC BY-NC-ND 4.0), which permits the noncommercial replication and distribution of the article with the strict proviso that no changes or edits are made and the original work is properly cited (including links to both the formal publication through the relevant DOI and the license). See: https://creativecommons.org/licenses/by-nc-nd/4.0/.

\section{References}

1. Singer M, Deutschman CS, Seymour CW, et al. The
Third International Consensus Definitions for Sepsis and Septic Shock (Sepsis-3). JAMA 2016;315:801-10.

2. Fernando SM, Rochwerg B, Seely AJE. Clinical implications of the Third International Consensus Definitions for Sepsis and Septic Shock (Sepsis-3). CMAJ 2018;190:E1058-9.

3. L'Heureux M. Sepsis-Induced Cardiomyopathy: a Comprehensive Review. Curr Cardiol Rep 2020;22:35.

4. Poveda-Jaramillo R. Heart Dysfunction in Sepsis. J Cardiothorac Vasc Anesth 2021;35:298-309.

5. Walley KR. Sepsis-induced myocardial dysfunction. Curr Opin Crit Care 2018;24:292-9.

6. Kim S, Lee J, Kim BK, et al. Association between Left Ventricular Systolic Dysfunction and Mortality in Patients with Septic Shock. J Korean Med Sci 2020;35:e24.

7. Hunter JD, Doddi M. Sepsis and the heart. Brit J Anaesth 2010;104:3-11.

8. Sato R, Nasu M. A review of sepsis-induced cardiomyopathy. J Intensive Care 2015;3:48.

9. Hawiger J. Heartfelt sepsis: microvascular injury due to genomic storm. Kardiol Pol 2018;76:1203-16.

10. Xie J, Wang H, Kang Y, et al. The Epidemiology of Sepsis in Chinese ICUs: A National Cross-Sectional Survey. Crit Care Med 2020;48:e209-18.

11. Pan J, Peng M, Liao C, et al. Relative efficacy and safety of early lactate clearance-guided therapy resuscitation in patients with sepsis A meta-analysis. Medicine 2019;98:e14453.

12. Innocenti F, Palmieri V, Guzzo A, et al. SOFA score and left ventricular systolic function as predictors of shortterm outcome in patients with sepsis. Intern Emerg Med 2018;13:51.

13. Kim JS, Kim M, Kim YJ, et al. Troponin Testing for Assessing Sepsis-Induced Myocardial Dysfunction in Patients with Septic Shock. J Clin Med 2019;8:239.

14. Nabzdyk CS, Couture EJ, Shelton K, et al. Sepsis induced cardiomyopathy: Pathophysiology and use of mechanical circulatory support for refractory shock. J Crit Care 2019;54:228-34.

15. Jeong HS, Lee TH, Bang CH, et al. Risk factors and outcomes of sepsis-induced myocardial dysfunction and stress-induced cardiomyopathy in sepsis or septic shock. Medicine 2018;97:e263.

16. Vallabhajosyula S, Pruthi S, Shah S, et al. Basic and advanced echocardiographic evaluation of myocardial dysfunction in sepsis and septic shock. Anaesth Intensive Care 2018;46:13-24.

17. Trof RJ, Danad I, Groeneveld AJ. Global end-diastolic 
volume increases to maintain fluid responsiveness in sepsis-induced systolic dysfunction. BMC Anesthesiol 2013;13:12.

18. Sanfilippo F, Corredor C, Fletcher N, et al. Left ventricular systolic function evaluated by strain echocardiography and relationship with mortality in patients with severe sepsis or septic shock: a systematic review and meta-analysis. Crit Care 2018;22:183.

19. Lanspa MJ, Cirulis MM, Wiley BM, et al. Right Ventricular Dysfunction in Early Sepsis and Septic Shock. Chest 2021;159:1055-63.

20. Cirulis MM, Liou TG, Ryan JJ. RV/LV ratio in severe sepsis and septic shock response to Letter to the Editor. J Crit Care 2019;50:311-2.

21. Ganter MT, Geisen M, Hartnack S, et al. Prediction of fluid responsiveness in mechanically ventilated cardiac surgical patients: the performance of seven different functional hemodynamic parameters. BMC Anesthesiol 2018; $18: 55$.

22. Seymour CW, Gesten F, Prescott HC, et al. Time to Treatment and Mortality during Mandated Emergency

Cite this article as: Wang Y, Zhai X, Zhu M, Pan Y, Yang M, Yu K, He B. Risk factors for postoperative sepsisinduced cardiomyopathy in patients undergoing general thoracic surgery: a single center experience. J Thorac Dis 2021;13(4):2486-2494. doi: 10.21037/jtd-21-492
Care for Sepsis. N Engl J Med 2017;376:2235-44.

23. Nguyen HB, Namita AKJ, Yataco AC, et al. Early goaldirected therapy in severe sepsis and septic shock: insights and comparisons to ProCESS, ProMISe, and ARISE. Crit Care 2016;20:160-76.

24. Khan RA, Khan NA, Bauer SR, et al. Association Between Volume of Fluid Resuscitation and Intubation in HighRisk Patients With Sepsis, Heart Failure, End-Stage Renal Disease, and Cirrhosis. Chest 2020;157:286-92.

25. Brown RM, Semler MW. Fluid Management in Sepsis. J Intensive Care Med 2019;34:364-73.

26. Jones TW, Smith SE, Van Tuyl JS, et al. Sepsis With Preexisting Heart Failure: Management of Confounding Clinical Features. J Intensive Care Med 2020;159:885066620928299.

27. Perdue SM, Poore BJ, Babu AN, et al. Successful use of extracorporeal membrane oxygenation support in severe septic shock with associated acute cardiomyopathy. J Card Surg 2018;33:50-2.

(English Language Editor: J. Reynolds) 